\title{
Denosumab Use in Chronic Renal Failure
}

\author{
Sezer SAĞLAM
}

Department of Medical Oncology, T.C. Demiroglu Bilim University Faculty of Medicine, Istanbul-Turkey

\section{Introduction}

Chronic kidney failure (CRF) is an organ failure caused by the complete loss of kidney function. The kidneys are the last organ where vitamin D is activated. Therefore, a chronic vitamin D3 (calcitriol) deficiency that cannot be activated can cause a variety of problems such as calcitriol deficiency, biochemical hyperparathyroidism, relatively low parathyroid hormone level, increased alkaline phosphatase (hyperphosphatemia), increased fibroblast growth factor-23, high bone turnover disease, adynamic bone disease, vascular calcification, hyperhypophosphatemia, and hyper-hypocalcemia.[1]

There are very few publications on its use in chronic renal failure. Most of earlier studies are case presentations. Denosumab's official website suggests that when creatinine clearance is below $30 \%$, the risk of hypocalcemia is high and it should be supplemented with calcium and vitamin D.[2]

In the multiple myeloma randomized study in which the most renal problems were experienced, we do not have information because the group with creatinine clearance below 30\% was not included because zoledronic acid was a control group.[3] The half-life of denosumab does not increase for patients with creatine clearance below 30\% in CRF.

In a study, when the effects of single dose denosumab injection in patients with impaired renal function were examined, $15 \%$ cases with hypocalcemia, $15 \%$ with extremity pain and $11 \%$ with nausea were reported without calcium and vitamin D supplements.[4]
Again, in a case report, CRF was found to correct osteoporosis with $60 \mathrm{mg}$ of denosumab, calcium and vitamin D every six months.[5]

Denosumab can be used in patients with CRF by closely monitoring the calcium level and giving active vitamin $\mathrm{D}$ (calcitriol).

\section{References}

1. Kalantar-Zadeh K, Shah A, Duong U, Hechter RC, Dukkipati R, Kovesdy CP. Kidney bone disease and mortality in CKD: revisiting the role of vitamin D, calcimimetics, alkaline phosphatase, and minerals. Kidney Int Suppl 2010;(117):S10-21.

2. https://www.pi.amgen.com/ /media/amgen/repositorysites/pi-amgen-com/xgeva/xgeva_pi.pdf

3. Raje N, Terpos E, Willenbacher W, Shimizu K, GarcíaSanz R, Durie B, et al. Denosumab versus zoledronic acid in bone disease treatment of newly diagnosed multiple myeloma: an international, double-blind, double-dummy, randomised, controlled, phase 3 study. Lancet Oncol 2018;19(3):370-81.

4. Block GA, Bone HG, Fang L, Lee E, Padhi D. A single-dose study of denosumab in patients with various degrees of renal impairment. J Bone Miner Res 2012;27(7):1471-9.

5. Dusilova Sulkova S, Horacek J, Safranek R, Gorun P, Viklicky O, Palicka V. Denosumab associated with bone density increase and clinical improvement in a long-term hemodialysis patient. Case report and review of the literature. Acta Medica (Hradec Kralove) 2014;57(1):30-3.
Accessible online at: www.onkder.org

OPEN ACCESS This work is licensed under a Creative Commons Attribution-NonCommercial 4.0 International License.
Dr. Sezer SAĞLAM

T.C. Demiroğlu Bilim Üniversitesi Tıp Fakültesi,

Tıbbi Onkoloji Anabilim Dalı,

Istanbul-Turkey

E-mail: saglam@istanbul.edu.tr 